\title{
Newcastle satisfaction with nursing scales: an instrument for quality assessments of nursing care
}

\author{
Lois H Thomas, Elaine McColl, Jonathan Priest, Senga Bond, Richard J Boys
}

\begin{abstract}
Objectives-To test the validity and reliability of scales for measuring patients' experiences of and satisfaction with nursing care; to test the ability of the scales to detect differences between hospitals and wards; and to investigate whether place of completion, hospital, or home influences response.

Design-Sample survey.

Setting-20 wards in five hospitals in the north east of England.

Patients-2078 patients in general medical and surgical wards.

Main measures-Experiences of and satisfaction with nursing care.

Results-75\% of patients approached to complete the questionnaires did so. Construct validity and internal consistency were both satisfactory. Both the experience and satisfaction scales were found to detect differences between randomly selected wards and hospitals. A sample of patients (102) were sent a further questionnaire to complete at home. $73 \%$ returned this; no significant differences were found in either experience or satisfaction scores between questionnaires given in hospital or at home.

Conclusion-Scales to measure patients' experiences of and satisfaction with nursing in acute care have been developed and found to be valid, reliable, and able to detect differences between hospitals and wards. Questionnaires can be given before patients leave hospital or at home without affecting scores, but those given at home have a lower response rate.

(Quality in Health Care 1996;5:67-72)
\end{abstract}

Keywords: nursing, patient satisfaction, psychometrics

\section{Introduction}

Understanding consumers' views is essential if any service is to be developed or improved. The importance of understanding what patients think about health care is clearly expressed in the United Kingdom Government's white paper Working for Patients, ${ }^{1}$ but there is still a gap between the objective of planning and delivering care "in a way which aims to meet the expressed wishes of patients" and the reality of doing so.

In nursing, developments such as the nursing process ${ }^{2}$ and primary nursing ${ }^{3}$ have as central tenets patient participation and choice in care, and the subsequent evaluation of the effectiveness or otherwise of care received. Patients' views of their care, summarised as satisfaction, are the most widely used measure of patient outcome. Patient satisfaction is also generally considered to be a legitimate measure of nursing quality: indeed, it has been described as the acid test which any system of delivering care must pass in evaluating effectiveness. ${ }^{4}$ The measurement of patient satisfaction forms an integral part of nursing quality assurance initiatives. ${ }^{5} 6$ However, our reviews of studies measuring patients' satisfaction with nursing ${ }^{7-9}$ reached the conclusion that there was no sensitive, valid, and reliable measure developed from patients' perspectives of patient satisfaction with nursing.

As a consequence, in 1993 we began a study which aimed to develop psychometrically sound measures of patients' experiences of and satisfaction with nursing from a patient's rather than a professional's perspective. These measures are intended for use by managers in quality assurance initiatives and by ward nurses and researchers to evaluate nursing interventions. We developed the Newcastle satisfaction with nursing scales (NSNS), and this paper reports their final tests.

Firstly, we sought to examine further the construct validity of the NSNS. Traditionally, the validity of a new measure is assessed by comparing results with those obtained from an established criterion or "gold standard" measure. However, no such measure was available. ${ }^{7-9}$ In such circumstances, the emphasis must be on construct validity, which can be assessed by examining expected variation in demographic and organisational variables ${ }^{10}$; this approach is generally termed "known group" validity. Previous research ${ }^{11-13}$ has suggested that older patients and patients who have spent less time in full time education tend to express more positive views of care received. Based on evidence from the qualitative phase of the study ${ }^{9}$ as well as previous research, ${ }^{8}$ we hypothesised that patients who could identify one nurse responsible for their care would express more positive experiences of and greater satisfaction with nursing care.

Secondly, we sought to show the internal consistency of the NSNS, expressed in terms of Cronbach's $\alpha^{14}$ and correlations between items and the total. ${ }^{10}$ Internal consistency is generally deemed to be adequate where Cronbach's $\alpha$ is greater than 0.7 and correlations and between items and total exceed $0 \cdot 4 .^{10}$ Most importantly, we sought further evidence of the power of the NSNS to detect differences between wards and hospitals.

A secondary aim was to assess whether the place that the questionnaire was given affects patients' responses. Previous research ${ }^{15}$ has 
suggested that place of questionnaire completion might influence both response rates and expressed levels of satisfaction. For example, patients may respond more positively in hospital thinking that their responses may influence subsequent care. An understanding of the effects of place of giving the questionnaire on response rates and response patterns is important to potential users, as there are major resource savings to be made if worthwhile data can be collected before patients leave hospital.

\section{Background}

A structured self completed questionnaire was developed by asking 150 patients, through individual and focus group interviews, what they perceived as good or bad quality nursing. ${ }^{9}$ Major themes to emerge were the availability and attentiveness of nurses, the degree of individual treatment afforded to patients, the provision of reassurance and information and the openness or informality of nurses. Other themes mentioned less often included nurses' professionalism and knowledge, ward organisation, and environment. The NUDIST software package for qualitative data analysis ${ }^{16}$ was used to code and group these themes. The concepts identified were used to create the item pool for the NSNS. With patients as expert informants, we ensured that the item content was important and relevant to their experience of nursing in acute hospitals. The use of many representative informants to generate and select items is a recognised means of establishing adequate content validity. ${ }^{17}$

The scales went through two phases of refinement and reduction. ${ }^{18}$ Recognised psychometric techniques ${ }^{10}$ were used to guide the reduction in items; those with poor internal consistency and high non-response rates were removed. ${ }^{18}$ Remaining items in each scale were subjected separately to factor analysis, which showed that each was one-dimensional: patients' experiences of all aspects of nursing care were highly correlated, as was their satisfaction with various aspects of nursing care, and individual concepts identified in qualitative interviews did not emerge as separate factors. Preliminary analysis ${ }^{19}$ suggested that the scales could detect differences in experience and satisfaction between wards and hospitals.

The scales were incorporated into a self completed questionnaire which comprised three sections:

1 EXPERIENCES OF NURSING CARE SCAI.F:

A series of 26 statements on aspects of nursing (outlined above) were presented and respondents were asked to indicate with a seven point Likert scale (box 1), how true each was of their own experience. To avoid affirmation bias, a mixture of 15 positively and 11 negatively worded statements were included. Responses across all items were summed and transformed to yield an overall experience score, with a potential range of $0-100$, where 100 represents the best possible experience.

2 SATISFACTION WITH NURSING CARE SCALL: Respondents rated their satisfaction with various aspects of nursing care, using a five point Likert scale (box 2). This section comprised 19 items. Responses across all items were summed and transformed to yield an overall satisfaction score of $0-100$, in which

\begin{tabular}{|c|c|c|c|c|c|c|}
\hline \multicolumn{7}{|c|}{1 Nurses gave me information just when I needed it } \\
\hline $\begin{array}{l}\text { Disagree } \\
\text { completely }\end{array}$ & $\begin{array}{c}\text { Disagree a } \\
\text { lot }\end{array}$ & $\begin{array}{l}\text { Disagree a } \\
\text { little }\end{array}$ & $\begin{array}{l}\text { Neither agree } \\
\text { nor disagree }\end{array}$ & Agree a little & Agree a lot & $\begin{array}{c}\text { Agree } \\
\text { completely }\end{array}$ \\
\hline 1 & 2 & 3 & 4 & 5 & 6 & 7 \\
\hline \multicolumn{7}{|c|}{2 Nurses used to go away and forget what patients had asked for } \\
\hline $\begin{array}{l}\text { Disagree } \\
\text { completely }\end{array}$ & $\begin{array}{c}\text { Disagree a } \\
\text { lot }\end{array}$ & $\begin{array}{l}\text { Disagree a } \\
\text { little }\end{array}$ & $\begin{array}{l}\text { Neither agree } \\
\text { nor disagree }\end{array}$ & Agree a little & Agree a lot & $\begin{array}{c}\text { Agree } \\
\text { completely }\end{array}$ \\
\hline 1 & 2 & 3 & 4 & 5 & 6 & 7 \\
\hline \multicolumn{7}{|c|}{3 Nurses checked regularly to make sure I was okay } \\
\hline $\begin{array}{c}\text { Agree } \\
\text { completely }\end{array}$ & Agree a lot & Agree a little & $\begin{array}{l}\text { Neither agree } \\
\text { nor disagree }\end{array}$ & $\begin{array}{l}\text { Disagree a } \\
\text { little }\end{array}$ & $\begin{array}{c}\text { Disagree a } \\
\text { lot }\end{array}$ & $\begin{array}{c}\text { Disagree } \\
\text { completely }\end{array}$ \\
\hline 1 & 2 & 3 & 4 & 5 & 6 & 7 \\
\hline \multicolumn{7}{|c|}{4 Nurses did not seem to know what each other was doing } \\
\hline $\begin{array}{l}\text { Disagree } \\
\text { completely }\end{array}$ & $\begin{array}{c}\text { Disagree a } \\
\text { lot }\end{array}$ & $\begin{array}{l}\text { Disagree a } \\
\text { little }\end{array}$ & $\begin{array}{l}\text { Neither agree } \\
\text { nor disagree }\end{array}$ & Agree a little & Agree a lot & $\begin{array}{c}\text { Agree } \\
\text { completely }\end{array}$ \\
\hline 1 & 2 & 3 & 4 & 5 & 6 & 7 \\
\hline
\end{tabular}

Box 1 Examples from "experiences of nursing" scale

\begin{tabular}{|c|c|c|c|c|c|c|}
\hline \multicolumn{2}{|r|}{ Thinking about your stay on the ward, how did you feel about: } & $\begin{array}{l}\text { Not at all } \\
\text { satisfied }\end{array}$ & $\begin{array}{c}\text { Barely } \\
\text { satisfied }\end{array}$ & $\begin{array}{c}\text { Quite } \\
\text { satisfied }\end{array}$ & $\begin{array}{c}\text { Very } \\
\text { satisfied }\end{array}$ & $\begin{array}{c}\text { Completely } \\
\text { satisfied }\end{array}$ \\
\hline 4 & The amount nurses knew about your care & 1 & 2 & 3 & 4 & 5 \\
\hline 5 & How quickly nurses came when you called for them & 1 & 2 & 3 & 4 & 5 \\
\hline 17 & How willing nurses were to respond to your requests & 1 & 2 & 3 & 4 & 5 \\
\hline 19 & Nurses' awareness of your needs & 1 & 2 & 3 & 4 & 5 \\
\hline
\end{tabular}

Box 2 Examples from "satisfaction with nursing" scale 
100 denoted complete satisfaction with all aspects of nursing care.

3 DEMOGRAPHIC INFORMATION

The final section elicited information about the patient and details of the stay in hospital.

\section{Methods}

PATIENTS

Two medical and two surgical wards were selected at random from each of five hospitals in the north east of England $(n=20)$. We deemed that a difference of at least $5 \%$ between wards in average scores on the experiences of nursing scale would indicate a difference in nursing care quality. Sample size calculations based on preliminary data suggested an achieved sample of 80 patients per ward was required to detect a difference of this magnitude with $80 \%$ power.

PATIENT RECRUITMENT

Patients were recruited on their day of discharge from hospital. All patients aged 18 years or older who had been in the ward for two nights or more and were not too confused or too ill to participate were approached by independent, trained data collectors, the study was explained, and they were invited to take part. Patients were encouraged to complete the quetionnaire before discharge and return it in a sealed envelope to a collection box in the ward. However, we recognised that some patients might not have enough time to complete the questionnaire before leaving the ward. We therefore used pre-paid envelopes (addressed to the University) and 322 (24\%) patients for whom these data were available completed the questionnaire at home and returned it by post. Of the total sample 558 $(29 \%)$ who received questionnaires in hospital did not fill in date of completion, so we cannot say where they completed the questionnaire. No reminders were used for this sample.

To assess whether place of completion affected response, a subsample of respondents were sent a second copy of the questionnaire to complete at home 10 days after discharge. According to preliminary calculations based on data derived from previous phases of questionnaire development, ${ }^{18}{ }^{19}$ a sample of 70 patients completing both questionnaires was required to detect a difference of $5 \%$ with $80 \%$ power. Anticipating an overall response rate of $70 \%$, a random sample of 102 respondents received a second, postal questionnaire; a single reminder, with a second copy of the questionnaire, was sent to those who had not responded after two weeks. Retrospective calculations based on observed variances for this final round of data collection indicated that achieved sample sizes of 42 and 48 patients would be adequate to detect an overall difference of $5 \%$ with $80 \%$ power in experience and satisfaction scores respectively.

\section{ANALYSIS}

Because experience and satisfaction scale scores were not normally distributed, KruskalWallis one way analysis of variance was used to find whether the scales were able to detect differences in patients' scores between hospitals and wards. To assess construct ("known group") validity, patients were categorised as under 40, 40-65, and over 65 years; we hypothesised that older patients would have higher experience and satisfaction scores. Similarly, we hypothesised that patients who had completed their full time education at 19 years or more (suggestive of third level education) would express less positive views. Finally, we expected that patients who could identify one specific nurse in charge of their care would have higher experience and satisfaction scores than those who could not or were unsure.

For the comparison between hospital and home, sample size calculations had allowed for the detection of a difference of $5 \%$ with $80 \%$ power. However, test-retest analysis ${ }^{19}$ yielded $95 \%$ confidence intervals (95\% CIs) of -13.6 to 14.0 for the experience scale and -13.8 to 15.6 for the satisfaction scale. We thus hypothesised that observed differences of more than 14 points (on the $0-100$ scale) between questionnaires answered in hospital or at home would indicate a real difference in experience or satisfaction scores at the level of the individual patient. The difference in scores was therefore calculated for each respondent; because these differences had a normal distribution, parametric statistical tests were used.

\section{Results}

RESPONSE RATES

Of 2078 eligible patients, 1920 (92\%) agreed to participate. An overall response rate of $75 \%$ (1559/2078) was obtained, representing $81 \%$ (1559/1920) of those agreeing to participate. Non-respondents were significantly more likely to be women (304 (58.6\%)) and were significantly older (mean age $62.2 v 59.8$ for respondents). There was no difference in duration of stay between the two groups. Response rates ranged from $67 \%$ to $91 \%$ per ward and from $69 \%$ to $89 \%$ per hospital.

\section{CONSTRUCT VALIDITY}

As there was no gold standard against which to compare scores derived from the NSNS, we assessed construct validity by examining expected variation related to age, educational attainment, and ability to identify a named nurse. Respondents' ages ranged from 18 to 97 (mean age 59.8, median age 64.0) years. Nearly half the sample $(707(45 \cdot 6 \%))$ was over the age of 65 years. Patients' age was significantly associated with experience scores $(\mathrm{P}<0.001)$ : older patients rated their experience of nursing more positively. However, there was no association between age and satisfaction scores $(P=0 \cdot 22)$.

A crude indicator of educational attainment was age at completion of full time education. A small percentage of respondents $(95(6 \cdot 7 \%))$ were aged 19 or over on leaving full time education. This variable was found to have a significant association with experience scores $(P<0.001)$ and satisfaction scores $(P<0.01)$. Those who left full time education earlier rated 
their experiences of and satisfaction with nursing care more positively.

Nearly half the sample $(700(47 \cdot 6 \%))$ could identify one particular nurse responsible for their care. When this was the case, patients reported more positive experiences of nursing $(\mathbf{P}=0.001)$ and rated their satisfaction with it more highly $(\mathrm{P}<0.001)$ than patients who could not identify a particular nurse.

\section{INTERNAL CONSISTENCY}

Cronbach's $\alpha$ was 0.91 for the experience scale and 0.96 for the satisfaction scale. This indicates that although internal consistency was good, further items could be removed without adversely affecting the scales. However, as the objective was to keep at least one question tapping each concept identified by patients as important to the quality of nursing, no further questions were removed. Correlations between single items and the total ranged from 0.31 to 0.69 for the experience scale (24 out of 26 exceeded 0.4 ) and from 0.53 to 0.82 for the satisfaction scale.

ABILITY TO DETECT DIFFERENCES

Generally patients rated their experiences of nursing care highly at both ward (fig 1 ; mean 84.6 , median 87.8 ) and hospital (fig 2) level. The experience scale was found to be able to detect differences between wards $(P<0.001)$ and hospitals $(P<0.001)$.

Patients were also highly satisfied with their nursing care (figs 3 and 4 ; mean $84 \cdot 1$, median $88 \cdot 2)$. The satisfaction scale was also found to detect differences between both wards $(P<0.001)$ and hospitals $(P<0.001)$.

To ensure that variations found between wards were due to differences in nursing quality, rather than in patient characteristics, analysis of covariance was performed with chronological age and age at leaving full time education as covariates. As data were not normally distributed, square root transformations were performed on experience and satisfaction scale scores (transformation $=$ square root of 100 minus experience/satisfaction score). Differences between wards and hospitals remained highly significant $(\mathbf{P}<0.001)$.

PLACE WHERE QUESTIONNAIRE WAS ANSWERED Seventy four patients $(73 \%)$ returned both questionnaires. However, as some patients had completed their first "in hospital" questionnaire at home after discharge, these patients were omitted from the analysis. The sample was reduced to 44 patients for the experience scale and 43 for the satisfaction scale analysis. The satisfaction scale sample size, although inadequate to detect differences between wards, was more than that required to detect a $14 \%$ difference (on the $0-100$ scale) at the level of the individual patient, the appropriate focus for this comparison. The relation between hospital and home assessments was examined by reference to the mean difference between scores in each setting for individual patients. With a paired $t$ test, no significant differences were found in either experience or satisfaction scores between questionnaires answered in hospital or at home $(P>0 \cdot 05)$.

\section{Discussion}

The final phase of our study has shown that the scales of patients' experiences of and satisfaction with nursing have good internal consistency and construct validity. The scales have proved capable of detecting differences

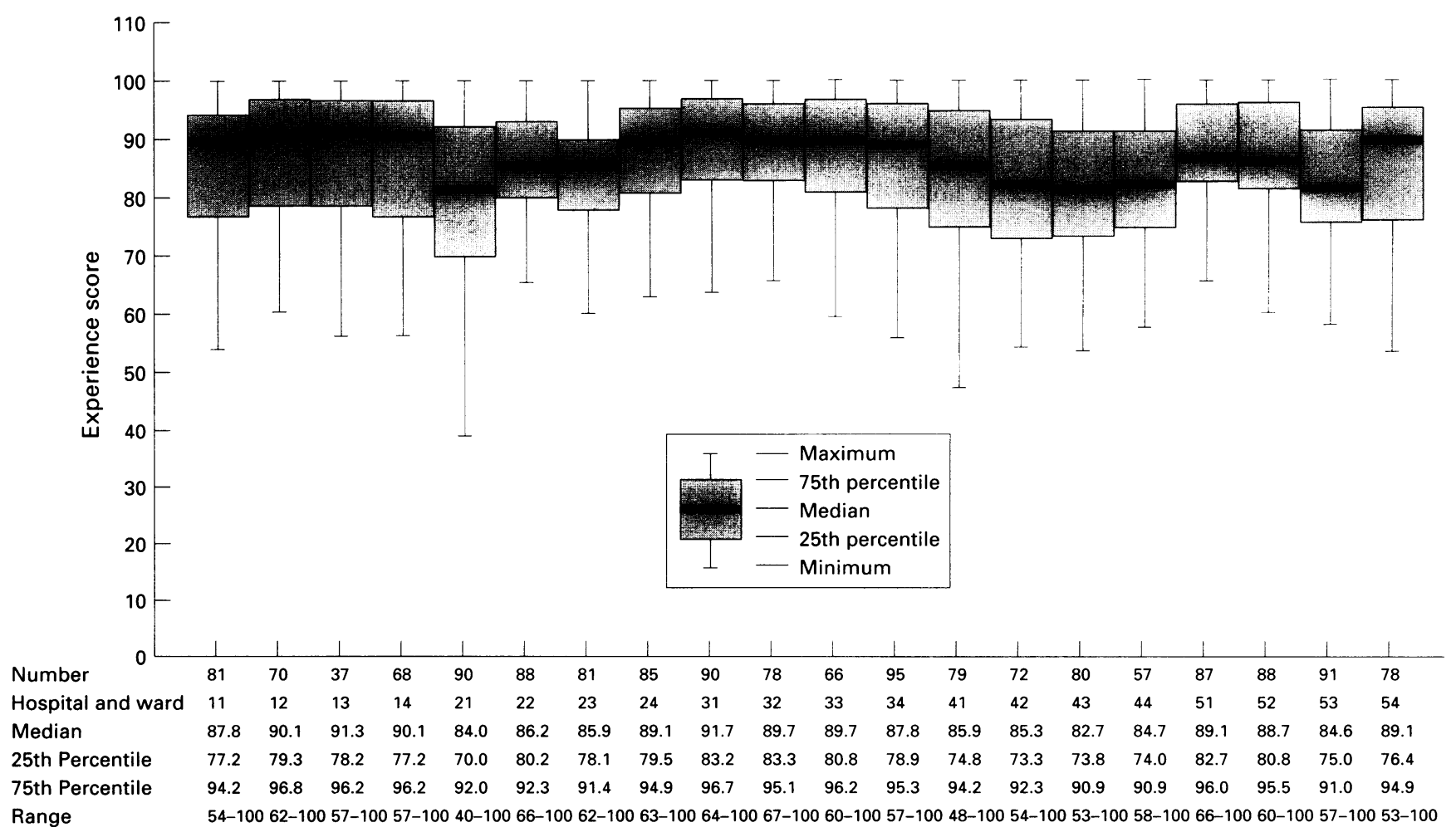




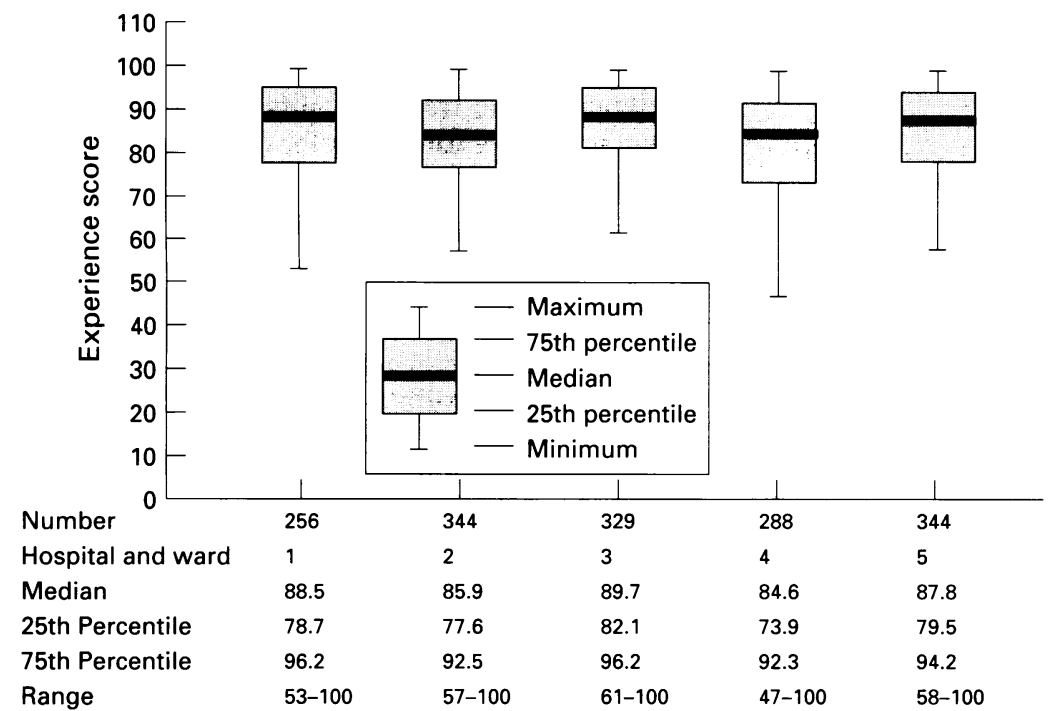

Figure 2 Box and whisker plots of experience score by hospital

between randomly selected wards and hospitals. Box 3 shows potential uses of the NSNS.

As with other scales measuring patient satisfaction, our scales provide relative, not absolute values. It is not possible, therefore, to attribute a universal or absolute interpretation to an observed score. The scales do, however, provide information about nursing quality from patients' perspectives. As well as overall scores, specific items in the scale - for example, questions regarding information can be used to monitor particular aspects of nursing practice. Scale scores could also be monitored over time to build up population norms. ${ }^{20}$

We found, as have others, ${ }^{11-13}$ that older patients rated their experiences of nursing more positively than younger patients. Older
- Comparing patients' experiences and satisfaction between wards, clinical

directorates, and hospitals

- Longitudinal comparisons (before and after a planned or unplanned intervention)

- As an outcome measure in randomised trials and other effectiveness studies

- Setting ward or hospital standards (a ward could aim for $85 \%$ of patients having a positive experience on questionnaire items)

- Auditing standards

- Measuring hypothesised improvements in nursing care following - for example, the introduction of a "named nurse" initiative this could be done by comparing median experience and satisfaction scores, but also individual questions where a change is expected.

Box 3 Potential uses of NSNS

patients did not, however, rate their satisfaction with nursing more positively. Patients who spent less years in formal education rated both their experiences of and satisfaction with nursing more highly than those who spent more time in full time education. ${ }^{11}$ Thus sample characteristics will have a bearing on scale scores achieved.

With the advent of the Patient's Charter, ${ }^{21}$ the concept of a named nurse should be a reality for every patient. We found that less than half our sample could identify a named nurse. However, those patients who could identify one nurse responsible for their care reported both more positive experiences of nursing and greater satisfaction than those who could not. Contributing factors may include one nurse being responsible for coordination of care and carer for a specific patient and the channelling of information through one source.

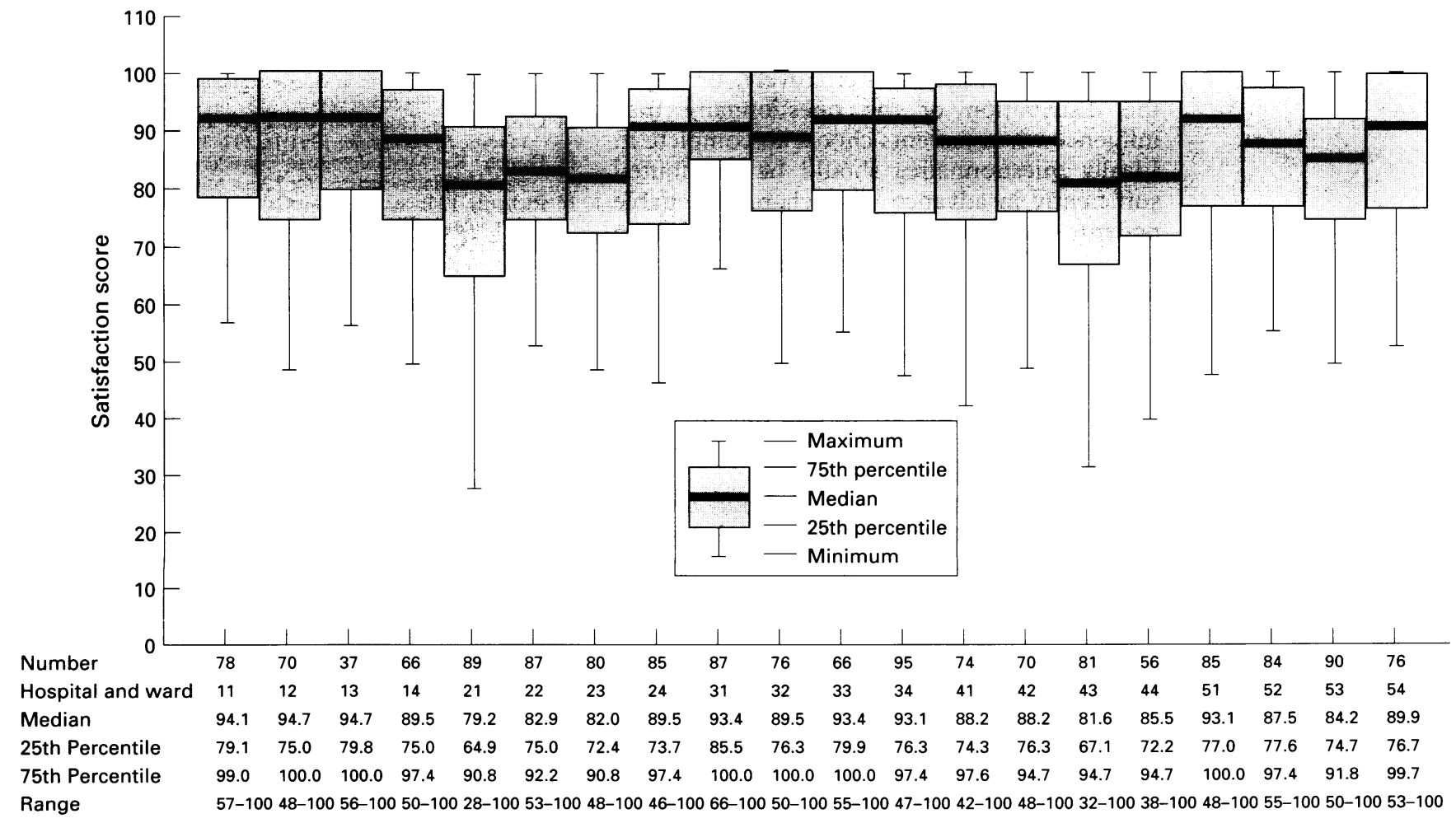

Figure 3 Box and whisker plot of satisfaction score by hospital and ward 


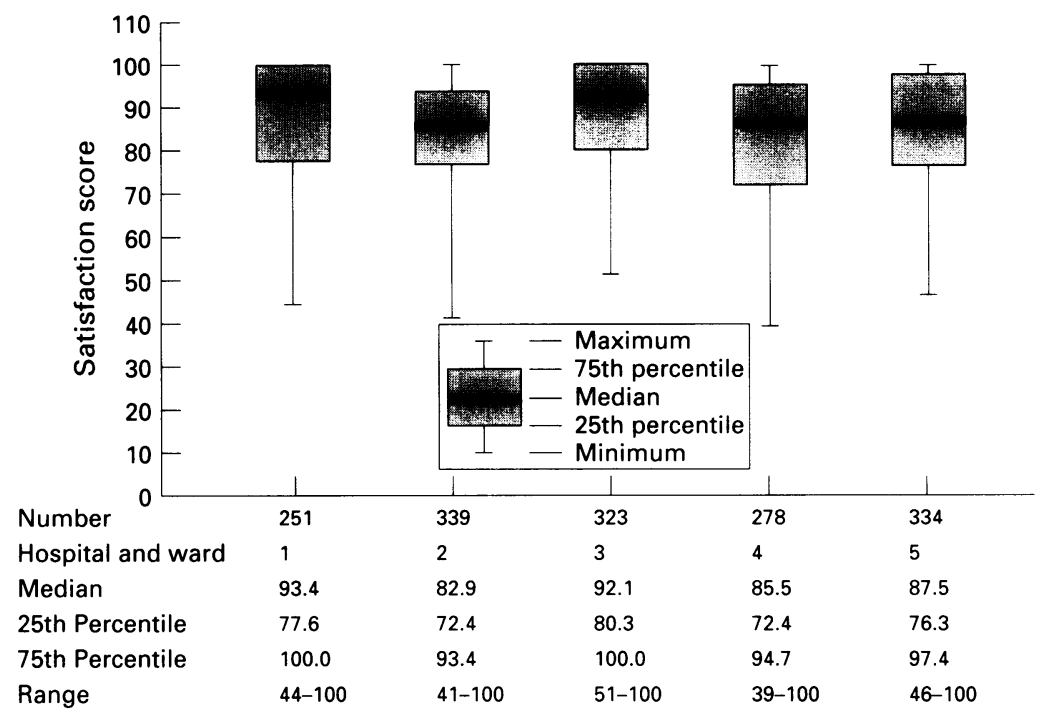

Figure 4 Box and whisker plot of satisfaction score by hospital

Place where the NSNS was answered (hospital or home) was not associated with experience or satisfaction scores. This suggests that the NSNS can be distributed to patients before they leave hospital without biasing either experience or satisfaction scores. Giving the questionnaires after discharge is more costly, involving postal charges and managing lists of addresses. Moreover, response rates from patients who have gone home are typically lower. Our overall response rate for patients completing questionnaires in hospital and at home was $73 \%$. This favourable rate could be due to patients having had personal contact with a researcher while still in hospital. Response rates for our test-retest analysis, ${ }^{19}$ when patients were contacted only by post, were lower ( $61 \%$ for the first questionnaire).

We found that many patients actually completed their "in hospital" questionnaire at home. We do not know why they did this. It is possible that respondents were concerned about confidentiality. Alternatively, timing of the distribution of the questionnaire may influence when patients choose to complete it. Ideally questionnaires should be distributed sufficiently in advance of discharge to enable patients to complete and return them while in hospital. It is not always possible in practice to predict when discharge will take place. We also suggest that questionnaires are distributed to an independent person rather than a member of the ward staff, that appropriate reassurances of confidentiality are given, and that mechanisms for assuring confidentiality (for example, sealed envelopes) are used.

We have been successful in our aim of developing scales for measuring patients' experiences of and satisfaction with nursing in acute hospital care, which can detect differences between hospitals and wards. We have no evidence of the transferability of the scales to other settings - for example, community care. Independent studies would be required for each setting to ensure that scales reflect the views of patients.

The NSNS package is now available at nominal cost. This comprises a master copy of the questionnaire, a user's manual, and computer software for data entry and analysis. The software allows the production of comparative output, contrasting patients' experiences and levels of satisfaction between clinical units.

We thank all the patients who took part in the study; the Department of Health, and Northern and Yorkshire Regional Health Authority Research and Development Divisions who funded this work; the fieldworkers who recruited patients; and Cath Brennand who managed the survey and produced the manuscript. The opinions expressed are ours and do not necessarily represent the views of the funding bodies.

1 Secretaries of State for Health. Working for patients. London HMSO, 1989.

2 Yura $\mathrm{H}$, Walsh MB. The nursing process. New York: Appleton-Century-Crofts, 1978.

3 Pearson A. Primary nursing. London: Croom Helm, 1988.

4 Richards DA, Lambert P. The nursing process: the effect on patients' satisfaction with nursing care. $\mathcal{f}$ Adv Nurs on patients satisfac

5 Lees GD, Richman J, Salauroo MA, Warden S. Quality assurance: is it professional insurance? $\mathcal{f} A d v$ Nur 1987;12:719-27.

6 Moores B, Thompson AGH. What 1357 hospital inpatients think about aspects of their stay in British acute hospitals. $\mathcal{7}$ Adv Nurs 1986;11:87-102.

7 Bond S, Thomas LH. Measuring patients' satisfaction with nursing care. 7 Adv Nurs 1992;17:52-63.

8 Thomas LH, Bond S. Outcomes of nursing care: the case of primary nursing. Int $\mathcal{F}$ Nurs Stud 1991;28:291-314

9 Thomas LH, MacMillan J, McColl E, Priest J, Hale C, Bond S. Obtaining patients' views of nursing care to inform the development of a patient satisfaction scale. Intermational fournal Quality in Health Care 1995. International

10 Streiner DL, Norman GR. Health measurement scales: a practical guide to their development and use. New York: Oxford University Press, 1989.

11 Greenley JR, Young TB, Schoenherr RA. Psychological distress and patient satisfaction. Med Care 1982; 4:373-85.

12 Cleary PD, Edgman-Levitan S, McMullen W, Delbanco TL. The relationship between reported problems and patient summary evaluations of hospital care. Oual Rev Bull 1992; February:53-9.

13 Chang BL, Uman GC, Linn LS, Ware JEJ, Kane RL. The effect of systematically varying components of nursing care on satisfaction in elderly ambulatory women. West $\mathcal{f}$ care on satisfaction in elderty
Nurs Res $1984 ; 6: 367-79$.

14 Cronbach LJ. Coefficient alpha and the internal structure of tests. Psychometrika 1951;16:297-334.

15 French K. Methodological considerations in hospita patient opinion surveys. Int f Nurs Stud 1981;18:7-32.

16 Richards T, Richards L, McGalliard J, et al. NUDIST 2.3 user manual. Eltham: Replee P/L, 1992.

17 Wilkin D, Hallam L, Doggett A. Measures of need and outcome for primary health care. Oxford: Oxford University Press, 1992

18 Priest J, McColl E, Thomas L, Bond S. Developing and refining a new measurement tool. Nurs Res 1995 2:69-81.

19 Thomas L, McColl E, Boys R, Priest J, Bond S. Final report to Northern and Yorkshire Research and Development Division: methodological and practical validation of the Newcastle satisfaction with nursing scales. Newcastle: Centre for Health Services Research, University of Newcastle upon Tyne, 1995.

20 Black N, Sanderson C. Day surgery: development of a questionnaire for eliciting patients' experiences. Quality in Health Care 1993;2:157-61.

21 Department of Health. The Patient's Charter and you. London: HMSO, 1995. 